\title{
O MODELO DE SALAS DE RECURSOS MULTIFUNCIONAIS: AVANÇOS E RETROCESSOS DE UMA REALIDADE EM CONSTRUÇÃO
}

\author{
THE RESOURCES MULTIFUNCTION ROOMS MODEL: PROGRESS AND \\ SETBACKS OF A REALITY UNDER CONSTRUCTION
}

\author{
Saulo Fantato MOSCARDINI ${ }^{1}$ \\ Adriana Maria Leone Alves OLIVEIRA ${ }^{2}$
}

RESUMO: O presente artigo objetiva discutir os avanços e retrocessos experimentados pela proposta de Sala de Recursos Multifuncionais em um município polo de formação para o Programa Educação Inclusiva: Atenção à Diversidade. Toma como base os resultados apresentados por dois estudos realizados nessa mesma realidade em períodos diferentes, organizando essas informações em categorias de análise voltadas para a observação das relações experienciadas nesse serviço de apoio. A comparação dos dados apresentados por essas investigações descreve um contexto no qual as mudanças sofridas por esse atendimento parecem se limitar a aspectos organizacionais, sem se preocuparem em oferecer as condições necessárias para que seja estruturado um trabalho que possibilite o pleno desenvolvimento do potencial de aprendizagem do aluno com deficiência.

PALAVRAS-CHAVE: Educação especial. Inclusão escolar. Salas de recursos multifuncionais.

ABSTRACT: This article aims to discuss the progress and setbacks experienced by the proposed Resources Multifunction Room in a municipality polo formation for the program Inclusive Education: Attention to Diversity. Takes as base the results of two studies conducted in this same reality in different periods, organizing information into categories of analysis directed to on the observation of relationships experienced this support service. The comparison of the data presented by these research describes a context where the changes undergone by this service seem to limit the organizational aspects, without bothering to offer the conditions necessary for it to be structured work that allows the full development of the potential for learning students with disabilities.

KEYWORDS: Special Education. School inclusion. Resources multifunction rooms.

\section{Introdução}

${ }^{1}$ Universidade Estadual Paulista (Unesp), Faculdade de Ciências e Letras, Araraquara - SP - Brasil. Doutorando no Programa de Pós-graduação em Educação Escolar. E-mail: s_moscardini@ yahoo.com.br.

${ }^{2}$ Universidade Estadual Paulista (Unesp), Faculdade de Ciências e Letras, Araraquara - SP - Brasil. Mestre pelo Programa de Pós-graduação em Educação Escolar. E-mail: adrianamlao@ @mail.com.

Doxa: Rev. Bras. Psicol. Educ., Araraquara, v.19, n.1, p. 128-148, jan./jun. 2017. ISSN: 1413-2060 
No trabalho que aqui se apresenta será analisada a forma como o processo de inclusão escolar vem sendo estruturado em um município de médio porte do interior paulista considerado polo de formação para o Programa Educação Inclusiva: Direito à Diversidade. Esta iniciativa de âmbito federal está voltada para a formação de educadores e gestores no intuito de torná-los capazes de transformar os sistemas educacionais em realidades inclusivas, o que passa pela garantia ao aluno com deficiência do direito de acesso e permanência com qualidade no ensino comum.

Dando especial atenção a relevância que a modalidade de Salas de Recursos Multifuncionais vem alcançando nesse contexto, procurar-se-á observar, contrapondo os dados coletados por Oliveira (2004) quando no início da estruturação dessa proposta de atendimento na cidade anteriormente indicada, com as observações realizadas por Moscardini (2011) sete anos depois nessa mesma realidade, os avanços e, principalmente, as lacunas e as questões problemáticas próprias a essa proposta de apoio. Apesar dos progressos legislativos alcançados pelo movimento inclusivo, questões iniciais que dificultam a aproximação entre o ensino comum e os serviços especializados com o objetivo de facilitar a inserção do sujeito com deficiência nesse ambiente ainda se mantém presentes, denunciando as contradições e as barreiras que devem ser enfrentadas pelo processo de inclusão se essa iniciativa pretende, de fato, se constituir como uma dinâmica emancipadora que se ocupe de preparar todos os sujeitos, independentemente das singularidades que possam apresentar, com as habilidades exigidas para que assumam papéis sociais relevantes.

\section{Apontamentos iniciais sobre o processo de inclusão escolar}

A partir dos debates contemporâneos que se ocupam de discutir esferas relacionadas ao campo da educação, se torna clara a importância que o processo inclusivo vem assumindo nessa realidade. Sendo aceita como a nova missão da escola, essa proposta, no entender de Bueno (2008), deve ser compreendida como uma iniciativa política em ação que corresponde à incorporação ao ensino comum dos alunos que tradicionalmente têm sido excluídos desse ambiente, o que pressupõe a compreensão da Educação Especial não mais como um sistema paralelo à escola regular, mas como condição que precisa estar presente em todos os níveis de aprendizagem, assumindo um caráter de transversalidade que perpassa todas as modalidades educacionais.

De acordo com Capelini (2001), a educação da pessoa com deficiência no Brasil se constituiu como centro de atenção e de preocupação apenas nos momentos nos quais dela 
sentiram necessidade os segmentos da sociedade. Dessa forma, essa autora chama a atenção para o fato de que, ao longo da história, muitas vezes as práticas identificadas com vista a incluir os sujeitos com deficiência no ambiente social do qual faziam parte, acabaram por contribuir ainda mais para a sua exclusão, mantendo-os a margem do contexto ao qual pertenciam. Essa realidade sofreu sensível alteração com a assunção do processo inclusivo como a nova bandeira democrática, o que ocorreu a partir da década de 1990, impondo o oferecimento de atendimentos voltados para as necessidades apresentadas pelos sujeitos nos quais esses indivíduos passam a apresentar suas dificuldades a sociedade, cabendo a ela suprir essas particularidades no intuito de garantir o desenvolvimento e o pleno exercício da cidadania por parte dessas pessoas.

Ao se questionar o atendimento oferecido à criança com deficiência em nosso país, não se pode perder de vista que, historicamente, o Estado Brasileiro atribuiu às instituições filantrópicas a iniciativa em fornecer serviços voltados à supressão das singularidades inerentes a esses sujeitos (JANNUZZI, 1997). Esse contexto sofreu consideráveis mudanças com a institucionalização do processo de inclusão que tem na Conferência Mundial Sobre Educação Para Todos, realizada em Jontiem/ Tailândia em 1990, um dos seus marcos primordiais. Esse evento, patrocinado pala UNESCO, UNICEF, PNUD e Banco Mundial, visou conscientizar os governos sobre a relevância da universalização da educação básica, firmando a Declaração Mundial Sobre a Educação para Todos e confirmando o Plano de Ação Para Satisfazer as Necessidades Básicas de Aprendizagem.

Da mesma forma que essa Conferência, a Declaração Sobre Princípios, Políticas e Práticas na Área das Necessidades Educativas Especiais, promulgada em Salamanca/Espanha, também possui importância central ao se analisar os princípios que regem o processo inclusivo. Elaborado em 1994, esse documento determina que os Estados elenquem todos os seus esforços políticos e financeiros no sentido de possibilitarem a melhoria de seus sistemas educacionais com vista a garantirem a inclusão de todas as crianças, independentemente das suas diferenças ou dificuldades individuais. Deixando claro que os governos devem instituir o princípio da educação inclusiva como forma de lei e/ou política, atribui a essa esfera a responsabilidade de matricular todas as crianças no ensino comum, a menos que existam fortes razões que inviabilizem esse processo, apontando a urgência de que seja afiançada à comunidade o direito de participar do planejamento e da tomada de decisões das questões relacionadas à provisão de serviços educacionais. Nessa Declaração a inclusão é concebida como o princípio básico que orienta as medidas propostas no contexto educacional, afirmando 
que todas as pessoas devem aprender juntas, independentemente das singularidades que possam apresentar.

A Convenção Interamericana para a Eliminação de Todas as Formas de Discriminação Contra a Pessoa Portadora de Deficiência, ocorrida na Guatemala no ano de 2001, também deve ser aceita como um importante acontecimento na luta pela inclusão do sujeito com deficiência, assumindo um peso regional considerável ao observarmos as discussões efetivadas no âmbito latino-americano e das quais o Brasil participou ativamente. Tendo como foco a defesa da impossibilidade de diferenciação tomando como base apenas um possível quadro de deficiência e a definição de discriminação como toda e qualquer distinção, exclusão ou restrição baseada em uma condição deficitária, preconizou, segundo Carneiro (2008), que o lugar do aluno com deficiência deve ser no ensino comum.

A influência que esses esforços internacionais em prol da garantia de atendimentos voltados para as necessidades das crianças que apresentam quadros deficitários exerceu sobre a legislação brasileira pode ser observada a partir da Lei de Diretrizes e Bases da Educação Nacional (LDB 9394/96) (BRASIL, 1996). Nesse documento é previsto o oferecimento de serviços especializados voltados para o acolhimento das urgências trazidas pela criança com deficiência que se encontra inserida na escola comum quando esses apoios se mostrarem necessários, estabelecendo que a oferta desse tipo de atendimento deve se mostrar presente em todos os níveis de ensino, sublinhando assim o caráter de transversalidade assumido pela Educação Especial que passa a ser orientada pela estruturação de iniciativas de apoio que devem ser ofertadas, preferencialmente, na rede regular de ensino (SAVIANI, 2008).

A disposição legal em afiançar a inclusão escolar do sujeito com deficiência também se mostra presente nos Parâmetros Curriculares Nacionais, no qual se reafirma o compromisso em oferecer aos alunos uma formação cidadã que seja orientada pelo respeito à diversidade que marca a espécie humana, destacando que a inclusão do indivíduo que apresenta uma condição deficitária demanda uma mudança social profunda que transcende a elaboração de uma legislação inclusiva, envolvendo a organização da sociedade em torno de princípios democráticos que garantam a todas as pessoas, independentemente das individualidades que possam apresentar, as condições necessárias para que desenvolvam plenamente sua autonomia física e intelectual, atribuindo-se à escola uma função central nesse processo (BRASIL, 1998).

No documento - Diretrizes Nacionais para a Educação Especial na Educação Básica -, elaborado em 2001 pela antiga SEESP (Secretaria de Educação Especial), atual SECAD (Secretaria de Educação Continuada, Alfabetização, Diversidade e Inclusão), é defendida a igualdade de condições para o acesso e permanência na escola independentemente das 
características próprias a cada aluno, especificando a obrigatoriedade do oferecimento de serviços especializados que possam suprir as singularidades apresentadas pelas crianças em situação de inclusão. A obrigação dos órgãos públicos em ofertar essas modalidades de apoio é ressaltada na Política Nacional de Educação Especial na Perspectiva da Educação Inclusiva ao pontuar que o movimento de inclusão escolar depende de uma mudança estrutural e cultural da escola, reconhecendo a segregação que caracteriza o modelo atual de ensino que organiza os alunos de acordo com suas características intelectuais, físicas, culturais, sociais e linguísticas (BRASIL, 2008).

Ao se deter sobre o estudo do momento atual pelo qual passa o movimento de inclusão escolar brasileiro, Pletsch (2010) aponta a ausência de clareza sobre o que deve ser aceito como "educação inclusiva", indicando que esse conceito está sendo compreendido como um processo no qual é atribuída somente à escola a responsabilidade de estruturar as condições para que o acesso e a permanência de todas as crianças nesse contexto seja viabilizado. Essa autora conclui que, apesar do discurso social e político corrente que defende a manutenção de dinâmicas inclusivas, as instituições escolares enfrentam dificuldades que impossibilitam a operacionalização de práticas voltadas para a inclusão, sendo negadas as condições necessárias para que essas iniciativas sejam viabilizadas.

Para Siqueira (2008) a determinação legal da matrícula do aluno com deficiência no ensino comum não foi acompanhada da elaboração de iniciativas que se mostrem capazes de avaliar o progresso alcançado por esses sujeitos nesse contexto, reafirmando que a discussão do processo inclusivo deve ser antecedida por um debate que esclareça os pilares sobre os quais o modelo de escola será erguido. Necessita pontuar os princípios que devem orientar a reordenação pedagógica pela qual essa realidade deve passar em busca de valores mais equitativos, uma vez que, de acordo com essa autora, o movimento de inclusão, ao invés de promover o pleno desenvolvimento físico e intelectual do aluno vem exercendo a função contrária, reiterando as incapacidades de aprendizagem demonstradas por esses indivíduos.

Diante de um contexto de discriminação no qual os sujeitos com deficiência nunca tiveram garantidas as condições ideais para que o seu progresso cognitivo fosse afiançado, a inclusão social dessa população supera a mera inserção em salas de aula comuns, demandando o questionamento das práticas educativas destinadas à escolarização dessas pessoas que se amparam na reprodução de um padrão didático que reforça iniciativas infantilizadoras que inviabilizam que esses sujeitos tenham contato com atividades que possibilitem o desenvolvimento do pensamento crítico a partir da experimentação de novas realidades (CHINALIA, 2006). 
A implementação de uma dinâmica inclusiva que de fato possibilite o pleno avanço das potencialidades físicas e cognitivas dos alunos com deficiência passa pelo debate do ambiente escolar de maneira que se torne uma realidade orientada pela necessidade de compreender o ser humano em todas as esferas envolvidas no seu avanço individual (biológica, social e cultural), superando assim uma concepção limitada e reducionista de desenvolvimento. O conhecimento por parte dos educadores das características do alunado que o ensino comum passa a acolher também é de vital importância para que esse processo possibilite o amadurecimento das habilidades necessárias para que a inserção social das pessoas com deficiência se processe, com base na estruturação de propostas de trabalho que objetivem que esses sujeitos se tornem membros ativos do contexto social ao qual pertencem.

\section{Salas de Recursos Multifuncionais conceito e evolução}

A adoção da Sala de Recursos na Educação Especial brasileira ocorreu na década de 1970, quando esta se tornou conhecida por meio da tradução de bibliografia americana especializada (SILVA, 2003). Nesse período surge um movimento voltado para o questionamento dos serviços ofertados aos sujeitos com deficiência, passando a considerar esse quadro como estando diretamente relacionado aos fatores ambientais e à resposta educacional mais adequada. Esta nova perspectiva, denominada Integração, atribui maior importância aos processos de aprendizagem dos alunos e às dificuldades encontradas para o seu progresso (MARCHESI; MARTÍN, 1995). Com esta nova concepção, as crianças que apresentam quadros deficitários passam a ser integradas à rede regular de ensino, sendo segregadas apenas aquelas mais seriamente comprometidas.

Em seu trabalho sobre as relações entre ensino, aprendizagem e deficiência intelectual, cujo objetivo foi refletir sobre a prática pedagógica da Sala de Recursos e das classes comuns durante o período no qual a Educação Especial era regida pelo paradigma da integração, com o intuito de esclarecer as questões referentes à cultura escolar, à inserção na escola e ao aprendizado de sujeitos com deficiência, Silva (2003, p. 31) aponta que, nessa realidade:

Os teóricos, de um modo geral, sustentavam a idéia de que o professor especializado era uma peça extremamente importante no movimento da sala de recursos. A qualidade de ensino e aprendizagem estava dependente da relação que ele mantinha com o professor da sala do ensino comum.

Neste sentido, a Política Nacional de Educação Especial definia Sala de Recursos como: 
Local com equipamentos, materiais e recursos pedagógicos específicos à natureza das necessidades especiais do alunado, onde se oferece a complementação do atendimento educacional realizado em classes do ensino comum. $\mathrm{O}$ aluno deve ser atendido individualmente ou em pequenos grupos, por professor especializado, e em horário diferente do que frequenta no ensino regular. (BRASIL, 1994, p. 21).

Portanto, inicialmente e durante todo o espaço de tempo no qual as políticas educacionais brasileiras se pautaram pelo princípio da integração escolar das crianças que apresentavam quadros deficitários, a Sala de Recursos foi compreendida como sendo um atendimento centrado nas deficiências, se ocupando de oferecer um espaço diferenciado de ensino voltado para a estruturação de iniciativas que se orientavam por uma perspectiva de entendimento discrepante das possibilidades de aprendizagem dos alunos com deficiência. Posteriormente, esse entendimento começou a ser alterado devido a uma mudança de paradigma que introduziu novos padrões educativos a partir da definição do princípio da escola para todos. Essa nova concepção educacional, assumida como um processo de inclusão escolar de todos os alunos, independentemente das singularidades que possam encerrar, indica a urgência da construção de uma escola que seja capaz de enfrentar e de lidar com as diferenças de qualquer natureza: de raça, gênero, condições sociais e alterações orgânicas (SILVA, 2003) ${ }^{3}$.

As políticas educacionais têm indicado que a escolarização das crianças com deficiência deve ocorrer, preferencialmente, na rede regular de ensino, assumindo a responsabilidade em estruturar serviços especializados que atendam às demandas trazidas por essa população, possibilitando o pleno desenvolvimento do seu potencial de aprendizagem (BRASIL, 1988, 1994, 1996). Nesse contexto, a Sala de Recursos, aceita pelo Ministério da Educação como o principal instrumento na luta pelo favorecimento da escolarização inclusiva de alunos com deficiência e atualmente denominada de Sala de Recursos Multifuncionais, assume papel de destaque ao discutirmos os avanços e retrocessos que o movimento inclusivo vem experimentando em nosso país ${ }^{4}$.

Esse atendimento é definido pela política educacional brasileira atual como:

\footnotetext{
${ }^{3} \mathrm{O}$ conceito de inclusão apresentado diferencia-se do conceito de integração. Este último tem como pressuposto as características dos indivíduos deficientes como informativas de suas possibilidades de incorporação ou não pelo ensino comum. Já o conceito de inclusão coloca a questão da incorporação desses indivíduos pelo ensino comum no reconhecimento da existência das mais variadas diferenças, para além da determinação biológica.

${ }^{4}$ O termo Sala de Recursos Multifuncionais é utilizado pela primeira vez na Resolução CNE/ CEB 4/2009 que institui as Diretrizes Operacionais para o Atendimento Educacional Especializado na Educação Básica: modalidade Educação Especial, em substituição a denominação Sala de Recursos.
} 
[...] serviço de natureza pedagógica, conduzido por professor especializado, que suplementa (no caso dos superdotados) e complementa (para os demais alunos) o atendimento educacional realizado em classes comuns da rede regular de ensino. (BRASIL, 2001).

Correspondendo a uma modalidade na qual o atendimento educacional especializado que deve ser oferecido ao aluno com deficiência inserido no ensino comum é estruturado, essa iniciativa de apoio busca trabalhar conteúdos que não são enfocados na classe comum, mas que são essenciais para que as demandas trazidas por esse público sejam atendidas, tornandoo apto a fazer frente às necessidades acarretadas pela sua inserção na escola comum. Não tendo como meta substituir a escolarização regular, a Sala de Recursos Multifuncionais é aceita como um direito garantido a todos os sujeitos que necessitarem em algum momento das suas vidas escolares desse apoio sistematizado que deve disponibilizar os recursos de acessibilidade e as estratégias capazes de eliminar as barreiras enfrentadas por esses indivíduos que dificultam a sua plena participação social.

De acordo com o Decreto 7611, de 17 de novembro de 2011 que institui as bases sobre as quais essa proposta de apoio se baseia, as Salas de Recursos Multifuncionais devem se organizar de acordo com as dificuldades inerentes a sua população, estruturando o atendimento de forma individual ou em pequenos grupos congregando alunos que apresentam as mesmas barreiras. Compreendido como parte integrante do sistema de ensino, esse serviço precisa estar presente no Projeto Político Pedagógico da escola, atestando a relação de proximidade que deve existir entre o ensino comum e as propostas de apoio para que a inserção escolar do aluno com deficiência seja garantida (BRASIL, 2011).

Tendo como meta fomentar recursos metodológicos que sejam capazes de eliminar possíveis barreiras ao processo de ensino-aprendizagem, promovendo condições de acesso, permanência e aprendizagem no ensino comum aos alunos com deficiência, a Sala de Recursos Multifuncionais deve ser interpretada como um ambiente dotado do mobiliário, do equipamento e dos materiais pedagógicos e didáticos necessários para a oferta do atendimento educacional especializado que deve contribuir para a inclusão escolar de crianças com deficiência.

Esse serviço, oferecido por professores especialistas, cujas funções são de identificar, estruturar e organizar iniciativas que atendam as urgências trazidas pelos alunos que frequentam essa realidade, avaliando a aplicação dos recursos pedagógicos que sejam capazes de promover a autonomia desses sujeitos no ambiente comum de ensino e nos demais 
contextos próprios a sua vida cotidiana, é organizado em dois grupos diferentes voltados para o atendimento de públicos discrepantes: tipo 1, que possui entre o seu equipamento computadores, monitores, fones de ouvido, impressora e todo o instrumental necessário para a oferta de serviços para alunos que apresentam todos os possíveis quadros de deficiência, menos a deficiência visual; e o tipo 2, que apresenta os aparelhos expostos anteriormente acrescido do material que viabiliza o atendimento das crianças que possuem deficiência visual.

Além das obrigações já descritas, cabe ao educador responsável pelo trabalho implementado na Sala de Recursos Multifuncionais elaborar conjuntamente com o docente do ensino comum, planos de trabalho voltados para a supressão das dificuldades inerentes aos alunos com deficiência, empreendendo um debate amplo no qual toda a equipe escolar esteja inserida, permitindo assim que seja construído um trabalho interdisciplinar e colaborativo no qual os objetivos específicos do ensino ofertado às crianças em situação de inclusão possam ser alcançados. Essas propostas devem prever o desenvolvimento e a avaliação de ações sincronizadas com a área da saúde, do esporte, da cultura e demais segmentos, ampliando o caráter multidisciplinar do atendimento oferecido a esses sujeitos (GOMES; POULIN; FIGUEIREDO, 2010).

\section{Método}

Esse artigo foi proposto a partir da contraposição dos dados coletados em dois estudos que se ocuparam de analisar o contexto da Sala de Recursos/ Sala de Recursos Multifuncionais estruturada em uma mesma rede de ensino, desenvolvidos em momentos distintos. Os resultados alcançados por Oliveira (2004) quando no início dessa proposta de atendimento no sistema educacional municipal pertencente a uma cidade de médio porte do interior paulista foram comparados com os dados coletados por Moscardini (2011), sete anos mais tarde, nessa mesma rede de ensino com o intuito de pontuar os avanços e as contradições experimentadas pela proposta de Sala de Recursos/ Sala de Recursos Multifuncionais (SRM) ${ }^{5}$.

Oliveira (2004) objetivou caracterizar a natureza da interação escola-família de crianças com necessidades educacionais especiais, a partir dos depoimentos de pais e professores. Participaram dessa investigação três professoras de sala de recursos e cinco

${ }^{5}$ O termo Sala de Recursos Multifuncionais é empregado apenas no trabalho de Moscardini (2011), enquanto Oliveira (2004) se vale da denominação Sala de Recursos. Como o artigo aqui em questão objetiva contrapor os dados coletados por essas pesquisas, durante a apresentação e a discussão dos resultados será utilizada a abreviatura SRM, fazendo referência aos dois ambientes educacionais descritos nas investigações analisadas. 
professoras de sala regular do ciclo I do ensino fundamental $\left(1^{\circ}\right.$ ao $5^{\circ}$ ano), em quatro escolas públicas, localizadas em um município de médio porte do interior paulista. $\mathrm{O}$ instrumento de coleta de dados utilizado foi a entrevista semi-estruturada. Em contrapartida, Moscardini (2011), buscando observar a relevância que o processo de ensino-aprendizagem de conteúdos formais vem assumindo no bojo do processo de inclusão escolar dos alunos com deficiência intelectual, analisou se estão sendo garantidas as condições imprescindíveis para o pleno desenvolvimento cognitivo desses indivíduos. Tomando como lócus de estudo uma escola pertencente a rede pública municipal, essa investigação observou quatro crianças identificadas como possuindo deficiência intelectual pelas professoras especialistas responsáveis pela SRM que se encontravam matriculadas no I ciclo do ensino fundamental, acompanhando esses sujeitos tanto nas salas de aula comuns, quanto nos momentos nos quais frequentavam essa proposta de atendimento.

Com o objetivo de propiciar uma análise aprofundada desse serviço de apoio, enfocando, de modo especial, as relações que se estruturam nessa realidade, foram selecionados aqueles dados apresentados pelas pesquisas citadas que fornecem um quadro claro da forma como o relacionamento entre os vários atores envolvidos nessa dinâmica se organiza, caracterizando as relações mantidas entre os alunos com deficiência que frequentam esse atendimento e os professores especialistas responsáveis pela SRM, ao mesmo tempo em que se pontuam as condições que marcam o relacionamento existente entre esses educadores e seus colegas regentes de classes regulares e as singularidades próprias à relação que se observa entre a criança com deficiência e seus pares no ensino comum.

Essas informações se encontram organizadas em categorias de análise apontando as similaridades e as discrepâncias existentes entre os resultados, de forma a possibilitar ao leitor observar as mudanças pelas quais a proposta de SRM passou durante o espaço de tempo que separa essas duas investigações, atentando, de modo especial, para os problemas que marcaram o início desse serviço e que, ainda hoje, se fazem presentes.

\section{Resultados e discussão}

O processo de inclusão escolar, com a inserção da modalidade de SRM para atendimento de crianças com deficiência foi iniciado em 2001 no município alvo das investigações (OLIVEIRA, 2004). Nessa realidade esse serviço se encontra estruturado em escolas de Educação Infantil e de Ensino Fundamental, atendendo alunos com deficiência que também frequentam o ensino comum. 
De acordo com as informações apresentadas por Oliveira (2004), a organização das SRM obedece a um projeto para a área de Educação Especial que se orienta pela proposta de Escola Inclusiva. Para colocar em funcionamento esta iniciativa a Secretaria Municipal de Educação e Cultura nomeou uma coordenadora pedagógica da Área de Educação Especial e criou a Equipe de Apoio de Educação Especial que envolve uma educadora de creche, uma professora especializada em Educação Especial para as Escolas Municipais de Educação Básica (EMEBs) e duas professoras especializadas em Educação Especial para as Escolas Municipais de Educação Infantil (EMEIs).

Em um primeiro momento, a Secretaria Municipal de Educação e Cultura estruturou as SRM nas EMEBs e EMEIs onde se encontravam salas vagas. Posteriormente, passou a equipar esses ambientes com o material necessário para o atendimento das necessidades especiais dos alunos. Oliveira (2004) destaca que em 2003 a prefeitura do município mantinha dezessete SRM que atendiam duzentos alunos com deficiência. Esse serviço era definido pela coordenadora pedagógica da Área de Educação Especial como sendo um apoio técnicopedagógico especializado para que o sujeito com deficiência conseguisse acompanhar a sala comum, funcionando no contraturno e contando com um professor especializado que deveria trabalhar com as necessidades desse aluno, orientando o trabalho pedagógico a ser desenvolvido pelos docentes responsáveis pelas classes comuns nas quais essas crianças estavam matriculadas.

No inicio a responsabilidade pela avaliação e encaminhamento dos alunos para o serviço de apoio especializado era da coordenadora pedagógica da Área de Educação Especial e os professores especialistas deveriam trabalhar o mesmo conteúdo da sala comum, empregando materiais diferenciados que atendessem às necessidades dos alunos, realidade diferente daquela encontrada por Moscardini (2011). Os dados coletados por esse autor indicam algumas mudanças na forma como a SRM se organiza atualmente em comparação com a maneira como era operacionalizada no início do movimento inclusivo, deixando claro que a esse contexto não cabe mais a função de trabalhar o mesmo conteúdo enfocado pelo ensino comum, secundarizando esse tipo de iniciativa em prol de dinâmicas voltadas para o desenvolvimento de habilidades mais pragmáticas que possibilitem que os alunos com deficiência atendam as demandas trazidas pela sua vida cotidiana, amadurecendo as capacidades inerentes a uma vivência autônoma onde possam assumir papéis sociais relevantes. Nesse sentido, esse serviço é assumido como complementar ao trabalho desenvolvido na classe regular, procurando promover nas crianças com deficiência as habilidades necessárias para que atendam às necessidades inerentes a escolarização comum. 
O encaminhamento da criança para a SRM não se dá mais pela coordenadora pedagógica da Área de Educação Especial, sendo atribuída ao professor especialista a responsabilidade de identificar aqueles sujeitos que demandam atendimento especializado. Essa categorização ocorre tomando como base um protocolo de avaliação inicial no qual são pontuadas as potencialidades e, sobremaneira, as dificuldades de aprendizagem apresentadas pelas crianças encaminhadas para esse serviço de apoio, dando origem a um plano de atendimento especializado no qual o trabalho a ser realizado com essa criança é descrito. Esse trabalho respeita uma escala previamente organizada pelo professor especialista de forma que aqueles sujeitos que apresentam maiores dificuldades possam estar presentes na SRM com mais frequência, sistematizando o trabalho em torno de sessões individuais ou em grupos reduzidos que congregam crianças que apresentam quadros semelhantes.

As reformulações sofridas pela modalidade de SRM ao longo do processo de construção da proposta inclusiva poderão ser observadas com maior clareza a partir da contraposição dos dados coletados por Oliveira (2004) e por Moscardini (2011). Essa exposição será organizada em torno de categorias de análise que se detêm sobre temas específicos, colaborando assim para que as transformações pelas quais esse serviço de apoio passou sejam esclarecidas. Cabe sublinhar que essas categorias analíticas foram formuladas a partir dos dados coletados pelas investigações observadas, sendo comuns aos dois estudos.

\section{Categorias de análise}

1 - Relacionamento professores do ensino comum e docentes das SRM.

Oliveira (2004) em sua pesquisa de mestrado, ao analisar as concepções dos professores das classes regulares e da SRM sobre o relacionamento e a troca de experiência e apoio entre eles, constatou que existe um distanciamento entre estes profissionais. Esse afastamento ocorre devido à falta de um momento apropriado para a troca de informações e para o planejamento de atividades voltadas aos alunos por eles assistidos. Além disso, percebe-se que a SRM é vista pelas pessoas que compõem o ambiente escolar como uma atividade à parte da rede regular de ensino. Ela ocupa o mesmo espaço físico, mas não está integrada na proposta pedagógica da escola. Esta posição dos profissionais da educação regular é justificada pela concepção segregacionista que se tem em relação à Educação Especial. Devido a essa compreensão os educadores do atendimento especializado também 
são discriminados, ou seja, não têm apoio ou possibilidade de troca de informações com os pares.

As escolas em que se encontram as SRM, segundo os professores especialistas entrevistados por Oliveira (2004), não apresentam nenhum problema. No entanto, esses profissionais relatam um sentimento de isolamento dentro do ambiente escolar, denunciando a falta de espaço físico apropriado para seus alunos. Mas, segundo a concepção da maioria dos professores do ensino comum, eles realizam um trabalho conjunto com os educadores do serviço de apoio, o que fica claro no seguinte relato:

E uma das questões é o que você está trabalhando até... eu conversei com a Diana que é a professora de recursos dela, então a gente procura manter uma troca de informações, né, com uma certa frequência, e o objetivo geral é promover a independência dela. $\mathrm{E}$ isso eu estou vendo que ela está respondendo a isso de uma forma satisfatória. (OLIVEIRA, 2004, p. 107).

Pode-se constatar nesse relato que a professora, a partir das trocas de informações coma docente da SRM, consegue trabalhar as necessidades específicas da criança e observar o seu desenvolvimento. A partir das concepções dos educadores entrevistados pode-se observar que, apesar de ocorrer alguns momentos de diálogo entre os profissionais das salas regulares e os especialistas, a comunicação entre eles é muito precária. Ou seja, não há um momento apropriado para que possam planejar as atividades necessárias para que o aluno com deficiência atinja o seu potencial de desenvolvimento.

Essa proximidade que deve existir entre todos os atores envolvidos no processo de inclusão escolar, mas que necessita estar ainda mais presente entre os professores responsáveis pelas classes comuns e os docentes especialistas que atendem esse público na SRM também não foi observada por Moscardini (2011). Os dados coletados por esse autor durante o seu estudo denunciam o distanciamento existente entre essas esferas de ensino, apontando a inexistência de um diálogo sistemático entre essas realidades, o que acarreta sérias dificuldades para a estruturação de propostas de trabalho comuns voltadas para o desenvolvimento cognitivo da criança com deficiência. Observa-se que não há relação entre o trabalho desenvolvido na SRM quando comparado às iniciativas empreendidas no ensino comum, apontando para uma realidade na qual o atendimento especializado permanece sendo compreendido como um segmento paralelo à escolarização regular.

O afastamento que se faz presente entre essas modalidades educacionais é constantemente delatado tanto pelos docentes do ensino comum, quanto por seus colegas especialistas, que reclamam da falta de oportunidades nas quais possam se reunir para 
conversar a respeito dos alunos com deficiência que são comuns a esses profissionais. Ao que tudo indica, o único horário disponível para que esse encontro aconteça é o HTPC (Horário de Trabalho Pedagógico Coletivo) que acontece semanalmente, todavia, o tempo escasso no qual essa reunião ocorre dificulta que esses professores troquem experiências a respeito das crianças em questão, viabilizando assim a elaboração de propostas pedagógicas que persigam objetivos semelhantes. Os educadores responsáveis pelas salas regulares nas quais os alunos que apresentam quadros deficitários se encontram criticam o fato de não receberem o apoio necessário por parte dos educadores especialistas, o que dificulta a operacionalização de propostas pedagógicas que atendam as singularidades inerentes a essas crianças com vista a promoverem a aprendizagem desses sujeitos.

2 - Formação (ou qualificação) dos professores do ensino comum e das SRM.

Outro aspecto apontado por Oliveira (2004) e que merece destaque, é o despreparo dos professores, tanto do ensino comum quanto das SRM, em trabalhar com as questões impostas pelo processo de ensino-aprendizagem dos alunos com deficiência. A visão dos educadores das classes regulares sobre o movimento inclusivo é cercada de dúvidas em relação à aprendizagem dessas crianças em sala de aula, além de sinalizar a falta de conhecimento para trabalhar com elas, o que aponta para a necessidade de mudanças nos cursos de formação inicial para o magistério.

De acordo com os dados obtidos por Moscardini (2011), os docentes responsáveis pelas classes comuns não se encontram preparados para suprir as demandas de um público historicamente excluído do contexto escolar, como o formado por alunos com deficiência que apresentam necessidades educacionais especiais, enfrentando problemas em estruturar dinâmicas que atendam às particularidades inerentes a esses sujeitos. Essas barreiras podem ser compreendidas levando-se em consideração que esses profissionais não apresentam a formação adequada que os gabarite a suprir as singularidades próprias a esses alunos, realidade agravada por um contexto no qual os professores das SRM nem sempre se mostram preparados para acolher as dificuldades trazidas pelo seu colega regente do ensino comum que não sabe como trabalhar com a criança com deficiência, denunciando a incapacidade apresentada por esses especialistas, em função da formação lacunar que recebem, em atender a todas as urgências que o princípio inclusivo impõe ao cotidiano escolar.

O despreparo do professor especialista em responder a todas as situações acarretadas ao ambiente da escola pelo processo de inclusão se justifica, ao menos parcialmente, pela falta 
de apoio que esses docentes recebem dos órgãos públicos responsáveis pela implantação de políticas educacionais, não tendo o amparo necessário para que sejam capazes de superar as dificuldades com as quais se deparam na sua prática diária. Torna-se clara uma dinâmica segundo a qual a preocupação com aspectos burocráticos se sobrepõe a promoção das condições imprescindíveis para que o movimento inclusivo possibilite a autonomia das crianças por ele abarcadas, secundarizando o esforço que deve ser empreendido em torno da estruturação das condições ideais de trabalho que possibilitem a todos os atores envolvidos nesse processo, sobretudo, aos professores do ensino comum e da SRM, garantirem o desenvolvimento físico e intelectual dos alunos com deficiência.

3 - Relacionamento professores do ensino comum e alunos com deficiência.

Apesar das dificuldades e dúvidas que permeiam o trabalho docente no processo de inclusão, os professores das salas regulares relatam, na investigação de Oliveira (2004), que mantêm uma relação adequada com as crianças com deficiência, descrevendo a manutenção de laços marcados pelo respeito mútuo e pela amizade.

Essa realidade é consubstanciada por Moscardini (2011) ao apontar que, apesar das dificuldades enfrentadas por esses docentes em trabalhar com os alunos com deficiência que passam a ser inseridos no ensino comum, o relacionamento que estabelecem com esses sujeitos é extremamente positivo, sendo, via de regra, caracterizado pelo companheirismo. Esses profissionais tendem a dispensar a criança com deficiência o mesmo tratamento que reservam aos seus pares aceitos como normais, mesmo com as barreiras que inviabilizam que esses educadores garantam atenção individualizada a esse aluno em razão do número considerável de crianças que se encontra sob a sua tutela. O professor estabelece com a criança uma relação hierárquica onde é destacada a diferença de papéis existente entre eles, cabendo ao aluno respeitar essa discrepância mantendo o comportamento julgado adequado a ser assumido por uma criança que frequenta a escolarização regular.

4 - Relacionamento professores das SRM e alunos com deficiência.

Ao observar a relação construída entre os docentes especialistas e as crianças com deficiência por eles atendidas, Oliveira (2004) sublinha que esses profissionais classificam esse relacionamento como adequado, apesar de admitirem serem firmes quando necessário. Esse quadro também foi descrito por Moscardini (2011), destacando que a relação construída 
entre o professor da SRM e as crianças atendidas é marcada pela proximidade entre esses sujeitos. A interação entre esses atores ocorre de forma constante, estabelecendo-se entre eles o mesmo relacionamento hierárquico observado no ensino comum, entretanto, no atendimento especializado a distância que se mostra presente entre educador e aluno não se expõe de forma tão clara se comparada ao que pode ser notado nas salas regulares em razão de se estruturar entre esses indivíduos um relacionamento de cumplicidade onde se reconhecem como iguais.

\section{5 - Relacionamento aluno-aluno na SRM.}

A escola, enquanto instituição educativa, além de ser um espaço de aprendizagem, também é um local propício para a socialização das crianças. Nesse ambiente o aluno pode vivenciar todo tipo de experiência, como se envolver em brigas, fazer amizades e outros. Tendo isso em vista, Oliveira (2004) pontua que as crianças que frequentavam a SRM e que foram acompanhadas pela sua investigação tiveram envolvimento em brigas na escola durante o ano letivo. De acordo com os professores responsáveis por esse serviço de apoio, eram "briguinhas leves, de um mexer com o outro" (OLIVEIRA 2004, p.86), caracterizando a relação mantida entre essas crianças como "satisfatória", realidade corroborada por Moscardini (2011) ao indicar que o relacionamento que se estrutura entre os alunos no interior da SRM é marcado pela igualdade, à medida que esses atores identificam a posição de equidade na qual se encontram.

6 - Relacionamento aluno-aluno com deficiência no ensino comum.

Os dados coletados por Oliveira (2004) descrevem uma realidade na qual as crianças com deficiência inseridas no ensino comum não são alvo de gozações ou piadinhas por parte dos seus colegas de classe, conceituando como "saudável" a relação mantida entre esses sujeitos, de acordo com a concepção das professoras das salas de ensino comum, situação diferente daquela acompanhada por Moscardini (2011). Os resultados apresentados por esse autor indicam que o relacionamento estruturado entre os alunos com deficiência e seus colegas no ambiente da classe regular se caracteriza pela quase inexistência de interação, apesar do esforço constante que os sujeitos em situação de inclusão exercem no sentido contrário. Essa divergência nos resultados pode ser explicada pela diferença na forma de coleta de dados realizada pelos autores. Moscardini (2011) fez observação de campo enquanto que Oliveira (2004) fez entrevistas com docentes e familiares. 
Nas salas de ensino comum observadas por Moscardini (2011) as crianças com deficiência foram vítimas constantes de práticas discriminatórias que ilustram a dificuldade que esses indivíduos enfrentam em se inserirem na dinâmica própria ao contexto no qual se encontram, indicando a falácia de um processo inclusivo que defende a socialização da criança que apresenta condições deficitárias como o primeiro passo rumo a plena inclusão social dessas pessoas.

A seguir será apresentado um quadro que representa a tentativa de síntese comparativa dos dados, oferecendo uma definição das categorias de análise estruturadas.

Quadro 1: Resultados encontrados por Oliveira (2004) no início do processo inclusivo em comparação com os dados de Moscardini (2011)

\begin{tabular}{|c|c|c|c|}
\hline Categoria & Definição & $\begin{array}{l}\text { Resultados obtidos } \\
\text { por Oliveira (2004) }\end{array}$ & $\begin{array}{c}\text { Resultados obtidos } \\
\text { por Moscardini (2011) }\end{array}$ \\
\hline $\begin{array}{l}\text { Relacionamento entre } \\
\text { os professores do } \\
\text { ensino comum e das } \\
\text { SRM. }\end{array}$ & $\begin{array}{l}\text { Objetiva } \\
\text { caracterizar a } \\
\text { relação mantida } \\
\text { entre o professor } \\
\text { especialista e seu } \\
\text { colega regente de } \\
\text { classes comuns, } \\
\text { pontuando o } \\
\text { distanciamento } \\
\text { existente entre } \\
\text { esses profissionais. }\end{array}$ & $\begin{array}{c}\text { Comunicação } \\
\text { precária }\end{array}$ & Comunicação precária \\
\hline $\begin{array}{l}\text { Formação (ou } \\
\text { qualificação) dos } \\
\text { professores do ensino } \\
\text { comum e das SRM. }\end{array}$ & 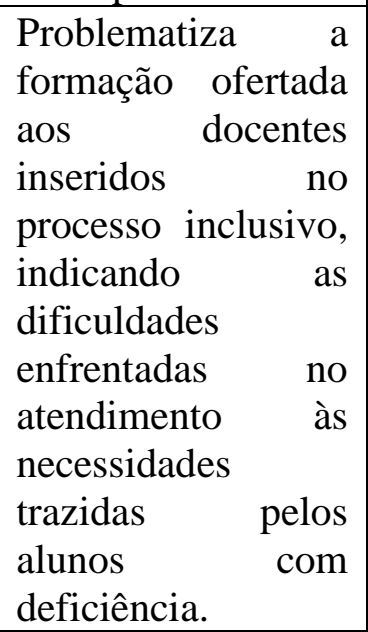 & $\begin{array}{lr}\text { Despreparo } & \text { para } \\
\text { atender as demandas } \\
\text { do aluno } & \text { com } \\
\text { deficiência } & \mathrm{e} \\
\text { formação } & \\
\text { inadequada. } & \end{array}$ & $\begin{array}{l}\text { Despreparo para } \\
\text { atender as demandas do } \\
\text { aluno com deficiência e } \\
\text { formação inadequada. }\end{array}$ \\
\hline $\begin{array}{l}\text { Relacionamento } \\
\text { professores do ensino } \\
\text { comum e aluno com } \\
\text { deficiência. }\end{array}$ & $\begin{array}{l}\text { Analisa como o } \\
\text { professor da sala } \\
\text { regular se relaciona } \\
\text { com a criança com } \\
\text { deficiência, } \\
\text { pontuando } \\
\text { características }\end{array}$ & Adequado & $\begin{array}{l}\text { Próximo, marcado pelo } \\
\text { companheirismo. }\end{array}$ \\
\hline
\end{tabular}

Doxa: Rev. Bras. Psicol. Educ., Araraquara, v.19, n.1, p. 128-148, jan./jun. 2017. ISSN: 1413-2060 


\begin{tabular}{|c|c|c|c|}
\hline & dessa relação. & & \\
\hline $\begin{array}{l}\text { Relacionamento } \\
\text { professores das } \\
\text { e aRM } \\
\text { deficiência. }\end{array}$ & 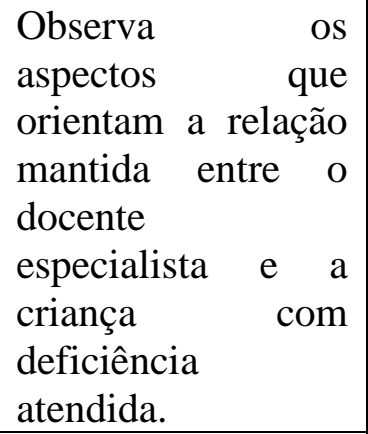 & Adequado & $\begin{array}{l}\text { Próximo, marcado pelo } \\
\text { companheirismo e por } \\
\text { práticas igualitárias. }\end{array}$ \\
\hline $\begin{array}{l}\text { Relacionamento } \\
\text { aluno-aluno na SRM. }\end{array}$ & \begin{tabular}{lr}
\multicolumn{2}{l}{ Questiona } \\
maneira como as \\
crianças atendidas \\
conjuntamente na \\
SRM r r a \\
relacionam.
\end{tabular} & Satisfatório & $\begin{array}{l}\text { Satisfatório, } \\
\text { caracterizado por uma } \\
\text { relação de igualdade. }\end{array}$ \\
\hline $\begin{array}{l}\text { Relacionamento } \\
\text { aluno-aluno com } \\
\text { deficiência no ensino } \\
\text { comum. }\end{array}$ & $\begin{array}{lr}\text { Descreve } & \text { como o } \\
\text { aluno } & \text { com } \\
\text { deficiência inserido } \\
\text { em salas de } \\
\text { comuns aula } \\
\text { relaciona com seus } \\
\text { pares tidos como } \\
\text { normais. }\end{array}$ & Satisfatório & 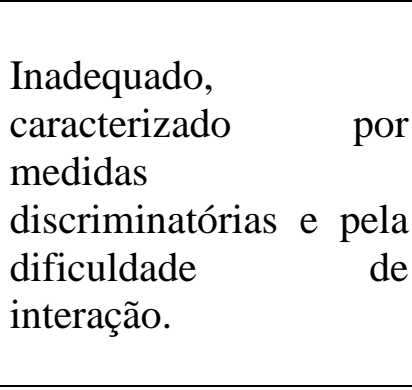 \\
\hline
\end{tabular}

Fonte: Elaboração própria.

\section{Conclusões}

Os dados aqui apresentados apontam para o fato de que o processo de inclusão pensado na realidade brasileira ainda apresenta alguns pontos que merecem ser melhor analisados e que possuem na sua solução um dos princípios centrais para que esse movimento avance rumo a real democratização do ensino. A construção desse projeto depende de uma profunda transformação sociocultural a partir da qual a diferença passe a ser compreendida como algo próprio ao gênero humano, assumindo que uma condição não pode ser aceita, como eminentemente positiva ou negativa, sem que avaliemos o contexto histórico no qual se encontra inserida.

Embora haja uma proposta de educação inclusiva no município estudado, pode-se constatar que a Sala de Recursos Multifuncionais, ainda que inserida no espaço físico da escola regular, continua funcionando à parte desta, ou seja, ela não foi incluída na proposta da escola como um todo. É preciso que esse serviço de apoio especializado seja incorporado à proposta da escola regular, pois o paradigma da inclusão propõe um sistema único de educação, no qual o ensino regular e o especial sejam integrados para favorecer a 
aprendizagem de todos os alunos, propiciando as condições necessárias para a troca de informações e conhecimentos entre os professores da SRM e seus colegas regentes do ensino comum.

Para se estruturar uma escola inclusiva é preciso que ela se modifique para receber e atender adequadamente os alunos com deficiência que passam a ser inseridos no ensino regular, viabilizando ações junto à sociedade para que esta se ajuste à convivência com a diversidade. É importante e necessário que os professores sejam capacitados para a efetivação da educação inclusiva, todavia, esta formação precisa ser contínua, pois o processo de inclusão representa uma mudança de paradigma em relação às pessoas com deficiência. E uma mudança de paradigma envolve uma mudança de concepção. E uma mudança de concepção demanda tempo e reflexão.

A criação de uma equipe de apoio especializada é outro fator muito importante para a implementação e efetivação de dinâmicas inclusivas, todavia, esta equipe precisa ser interdisciplinar. No contexto estudado constata-se que ela existe, mas é formada apenas por professores especializados em Educação Especial. É necessário que esta equipe seja ampliada para se ter um atendimento mais adequado e efetivo das necessidades apresentadas pelos alunos. Para isso, é preciso que se realize um trabalho conjunto com outros profissionais que também atuam com pessoas com deficiência, não somente na área da educação, mas também na área da saúde.

Nessa realidade as práticas educacionais também devem ser repensadas, sendo planejadas em torno não de um modelo inflexível e ideal de aluno, mas tomando por base as singularidades que caracterizam cada indivíduo, acolhendo esses aspectos como essenciais na luta por um sistema de ensino de fato inclusivo que não se contente com a mera inserção da criança com deficiência na escola regular, fornecendo todas as condições para que esses sujeitos tenham respeitado seu pleno potencial de aprendizagem, superando assim um modelo inclusivo irreal que se preocupa em divulgar uma dinâmica de inclusão mentirosa que em momento algum se ocupa de questionar as bases sobre as quais as práticas excludentes se amparam.

\section{REFERÊNCIAS}

BRASIL. Decreto lei $\mathrm{n}^{\circ} 7611$, de 17 de novembro de 2011. Dispõe sobre a educação especial, o atendimento educacional especializado e dá outras providências. Diário Oficial da União: República Federativa do Brasil. Brasília, DF, 17 nov. 2011. Disponível em: <planalto.gov.br/ccivil_03/Ato2011-2014/2011/Decreto/D7611.htm>. Acesso em: 7 mar. 2012. 
BRASIL. Ministério da Educação. Secretaria de Educação Especial. Política nacional de educação especial na perspectiva da educação inclusiva. Brasília, 2008.

BRASIL. Ministério da Educação. Secretaria de Educação Especial. Diretrizes nacionais para a educação especial na educação básica. Brasília, 2001.

BRASIL. Ministério da Educação. Secretaria de Educação Fundamental. Parâmetros curriculares nacionais: adaptações curriculares: estratégias para a educação de alunos com necessidades educacionais especiais. Brasília, 1998.

BRASIL.Lei n 9394, de 20 de dezembro de 1996. Estabelece as diretrizes e bases da educação nacional. Diário Oficial da União: República Federativa do Brasil. Brasília, DF, 20 dez. 1996. Disponível em: <http://www.planalto.gov.br/ccivil_03/leis/19394.htm>. Acesso em: 27 set. 2012.

BRASIL. Ministério da Educação. Secretaria de Educação Especial. PolíticaNacional deEducação Especial. Brasília, 1994.

BRASIL. Constituição da República Federativa do Brasil de 1988. Brasília, 1988. Disponível em:

<http://www.planalto.gov.br/ccivil_03/constituicao/ConstituicaoCompilado.htm>. Acesso em: 27 set. 2012.

BUENO, J. G. S. As políticas de inclusão escolar: uma prerrogativa da educação especial? In: BUENO, J. G. S.; MENDES, G. M. L.; SANTOS, R. A. (Org.). Deficiência e escolarização: novas perspectivas de análise. Araraquara: Junqueira \& Marin; Brasília: CAPES, 2008. p.4363.

CAPELINI, V. L. M. F. A inclusão de alunos com necessidades educacionais especiais em classes comuns: avaliação do rendimento acadêmico. 2001. 222f. Dissertação (Mestrado em Educação Especial) - Universidade Federal de São Carlos, São Carlos, 2001.

CARNEIRO, M. A. Decisões de algumas conferências internacionais sobre a educação inclusiva. In: CARNEIRO, M. A. O acesso de alunos com deficiência às escolas e classes comuns: possibilidades e limitações. 2.ed. Petrópolis: Vozes, 2008. p.33-38.

CHINALIA, F. Relações pedagógicas no contexto inclusivo: um olhar sobre a deficiência mental. 2006. 148f. Dissertação (Mestrado em Educação) - Universidade Metodista de Piracicaba, Piracicaba, 2006.

GOMES, A. L. L. V.; POULIN, J. R.; FIGUEIREDO, R. V. A educação especial na perspectiva da educação escolar: $o$ atendimento educacional especializado para alunos com deficiência intelectual. Brasília: Ministério da Educação: Secretaria de Educação Especial, 2010. (Coleção A Educação Especial na Perspectiva da Inclusão Escolar, v.2).

JANNUZZI, G. M. As políticas e os espaços para a criança excepcional. In: FREITAS, M. C. (Org.). História social da infância no Brasil. São Paulo: Cortez, 1997. p.183-223. 
MARCHESI, A.; MARTÍN, E. Da terminologia do distúrbio às necessidades educacionais especiais. In: COLL, C.; PALÁCIOS, J.; MARCHESI, A. (Org.). Desenvolvimento psicológico e educação: necessidades educativas especiais e aprendizagem escolar. Porto Alegre: ARTMED, 1995.

MOSCARDINI, S. F. Escolarização de alunos com deficiência intelectual em classes comuns e em salas de recursos multifuncionais. 2011. 194f. Dissertação (Mestrado em Educação Escolar) - Universidade Estadual Paulista, Faculdade de Ciências e Letras de Araraquara, Araraquara, 2011.

OLIVEIRA, A. M. L. A. A relação entre escola e família de crianças que frequentam salas de recursos: concepções de pais e professores. 2004. 184f. Dissertação (Mestrado em Educação Escolar) - Universidade Estadual Paulista, Faculdade de Ciências e Letras de Araraquara, Araraquara, 2004.

PLETSCH, M. D. Repensando a inclusão escolar: diretrizes políticas, práticas curriculares e deficiência intelectual. Rio de Janeiro: Nau Ed., 2010. (Coleção Docência, 1).

SAVIANI, D. A nova LDB: limites e perspectivas. In: SAVIANI, D. A nova lei da educação: LDB: trajetórias, limites e perspectivas. 11.ed. Campinas: Autores Associados, 2008. p.189-227.

SILVA, F. de C. T. As relações entre ensino, aprendizagem e deficiência mental: desenhando a cultura escolar. 2003. Tese (Doutorado em Educação: História, Política, Sociedade) - PontifíciaUniversidade Católica de São Paulo, São Paulo, 2003.

SIQUEIRA, B. A. Inclusão de crianças deficientes mentais no ensino regular: limites e possibilidades de participação em sala de aula. In: BUENO, J. G. S.; MENDES, G. M. L.; SANTOS, R. A. (Org.). Deficiência e escolarização: novas perspectivas de análise. Araraquara: Junqueira \& Marin; Brasília: CAPES, 2008. p.301-347.

\section{Como referenciar este artigo}

MOSCARDINI, Saulo Fantato.; OLIVEIRA, Adriana Maria Leone Alves. O modelo de salas de recursos multifuncionais: avanços e retrocessos de uma realidade em construção. Doxa: Rev. Bras. Psicol. Educ., Araraquara, v.19, n.1, p. 128-148, jan./jun. 2017. ISSN: 1413-2060.

Submetido em: 20/12/2016

Aprovado em: 30/03/2017 